УДК 811.11-26

\title{
СТИЛИСТИЧЕСКАЯ НЕЙТРАЛИЗАЦИЯ КАК ПРОБЛЕМА ХУДОЖЕСТВЕННОГО ПЕРЕВОДА (НА ПРИМЕРЕ «ТНЕ SНАDОW OVER INNSMOUTH» Г.Ф. ЛАВКРАФТА)
}

\author{
Шокин Григорий Олегович \\ аспирант \\ ФГБОУ ВО «Тверской \\ государственный университет»
}

\begin{abstract}
Аннотация: В статье рассмотрены примеры стилистической нейтрализации речевых характеристик в произведении американского писателя Говарда Лавкрафта «Тень над Иннсмутом» в различных переводах на русский язык. Приведены результаты сопоставительного анализа вариантов перевода для установления наиболее действенной переводческой методологии.
\end{abstract}

Ключевые слова: Речевые характеристики персонажей, стилистическая нейтрализация, сопоставительный анализ вариантов перевода.

\section{STYLISTIC NEUTRALIZATION AS A PROBLEM OF LITERARY TRANSLATION (ON THE EXAMPLE OF «THE SHADOW OVER INNSMOUTH» BY H.F. LOVECRAFT)}

\section{Shokin Grigoriy Olegovich}

\begin{abstract}
The article considers examples of stylistic neutralization of speech characteristics in the short novel of the American writer Howard Lovecraft «The Shadow over Innsmouth» in various translations into Russian. The results of a comparative analysis of various translations to establish an optional methodology are presented.
\end{abstract}

Key words: Speech characteristics of characters, stylistic neutralization, comparative analysis of translations.

Тексты научно-популярного и, в некоторых случаях, публицистического характера между автором и читателем устанавливают двусторонние 
отношения. Но в художественном тексте появляется третья сторона, посредники выражения и донесения авторской мысли - персонажи. Это полиморфные, наделенные параферналией отличительных черт образы, чьей проработке писатель, как правило, уделяет особое внимание.

Читатель может контактировать с персонажем как с помощью автора (косвенный контакт), так и без таковой (прямой контакт), и при прямом контакте средством является речь - прямой источник получаемой читателем информации, подчас не отягощенный каким-либо авторским комментарием. Воспринимая подобную не трактованную и никак не прокомментированную информацию по методу, называющемуся репродуктивным, читатель вырабатывает у себя определенное впечатление об особенностях характера персонажа.

Репродуктивное восприятие, в зависимости от контекста, может опираться на два обстоятельства. Первое - ситуативное, когда речь персонажа, лишенная отличительной эмоциональной окраски на протяжении произведения, в определенный момент видоизменяется, выказывая отклонения от официально зафиксированной письменно-литературной нормы языка и отражая изменения в эмоциональном состоянии персонажа; в таком случае речевая характеристика рассматривается не применительно к персонажу в целом, но к определенной речевой ситуации. Второе исключительное, когда речь персонажа по форме, равно как и по наполнению характеризует его не в определенной ситуации, а в обыденной манере взаимодействия, во всех настроениях и поступках.

Собственно, речевая характеристика - фактор, описывающий выбор отличительных лексических черт для каждого отдельно взятого персонажа литературного произведения, крайне выразительное средство художественного изображения [1]. В зависимости от авторского выбора синтаксические конструкции и лексика классической книжной речи могут быть заменены просторечной или даже обсценной лексикой, синтаксисом разговорного языка и повторяющимися речевыми оборотами, склонность к которым характеризует литературного героя с определенной профессиональной, социальной, общекультурной - стороны.

Один из наиболее углубленных путей всестороннего раскрытия характера литературного героя - его монологическая речь. Характеризуя персонажа через речь-монолог, писатели наиболее часто пользуются следующими способами: 


\section{ВСЕРОССИЙСКИЙ ФИЛОЛОГИЧЕСКИЙ ФОРУМ}

- «речевой лейтмотив» - мысли персонажа заняты некой внутренней проблемой, что находит отражение в его речи и делает очевидным его психологическое состояние (так, в речи Туркина в рассказе А.П. Чехова «Ионыч» часто повторяется слово «Недурственно...») [2];

- использование просторечий и искаженного написания некоторых слов - подобный прием чаще всего подчеркивает простоту происхождения, некую степень необразованности персонажа; так, в рассказе американского писателя-фантаста Роберта Блоха «You Got to Have Brains» главный герой использует слово «rowbot», искаженное «robot», рассуждая о новейших изобретениях эпохи. Перевод подобных речевых единиц «с ошибками»в соответствии с оригиналом полностью обоснован и рекомендуем;

- использование в речи героя иноязычных слов, чей смысл непонятен ему самому.

Как показывает сопоставительный анализ переводов и оригиналов, сохранение вышеупомянутых языковых тонкостей далеко не всегда соблюдается переводчиками; и даже трансформации на уровне стилистическом - компрессия (эллипсис, семантическое стяжение, устранение избыточных элементов и лексическое свертывание) и расширение текста, могут подчас навредить восприятию авторского текстуального посыла [6]. Как следствие, в речи персонажей в переводе теряются ее «портретные» особенности, появляются эмоционально-экспрессивные пробелы. Сравним переводы на русский язык и оригинальный текст повести американского писателя-мистика Говарда Филлипса Лавкрафта «Тень над Иннсмутом» («Тhе Shadow Over Innsmouth», 1936) [7, 3, 4].

\section{Таблица 1}

\section{Сравнение оригинального текста повести «Shadow Over Innsmouth»} и переводов, выполненных В. Бернацкой, С. Харитоновым, Ю. Розвадовским

\begin{tabular}{|c|c|c|}
\hline Оригинальный текст & Перевод В. Бернацкой & $\begin{array}{l}\text { Перевод С. Харитонова, } \\
\text { Ю. Розвадовского }\end{array}$ \\
\hline $\begin{array}{l}\text { «Wal, Sir, Obed he larnt } \\
\text { that they's things on this } \\
\text { arth as most folks never } \\
\text { heerd abaout - an' } \\
\text { wouldn't believe ef they } \\
\text { did hear. It seems these }\end{array}$ & $\begin{array}{l}\text { - Так вот что я вам скажу, } \\
\text { сэр. Абед узнал такое, о } \\
\text { чем не знал никто на } \\
\text { свете. Да и знал бы - не } \\
\text { поверил. Оказывается, } \\
\text { жители Канаки - так }\end{array}$ & $\begin{array}{l}\text { - Лады, сэр, Обед узнал, } \\
\text { щзто были там такие } \\
\text { люди, которых на земле } \\
\text { ищшо никто не видывал, } \\
\text { а даже если и услышит } \\
\text { кто о них, все равно }\end{array}$ \\
\hline
\end{tabular}




\begin{tabular}{|c|c|c|}
\hline $\begin{array}{l}\text { Kanakys was sacrificin' } \\
\text { heaps o' their young men } \\
\text { an' maidens to some kind } \\
\text { o' god-things that lived } \\
\text { under the sea, an' gittin' all } \\
\text { kinds o' favour in return. } \\
\text { They met the things on the } \\
\text { little islet with the queer } \\
\text { ruins, an' it seems them } \\
\text { awful picters o' frog-fish } \\
\text { monsters was supposed to } \\
\text { be picters o' these things. } \\
\text { Mebbe they was the kind o' } \\
\text { critters as got all the } \\
\text { mermaid stories an' sech } \\
\text { started. They had all kinds } \\
\text { o' cities on the sea-bottom, } \\
\text { an' this island was heaved } \\
\text { up from thar. Seems they } \\
\text { was some of the things } \\
\text { alive in the stone buildin's } \\
\text { when the island come up } \\
\text { sudden to the surface. } \\
\text { That's haow the Kanakys } \\
\text { got wind they was daown } \\
\text { thar. Made sign-talk as } \\
\text { soon as they got over bein' } \\
\text { skeert, an' pieced up a } \\
\text { bargain afore long». } \\
\text { «Them things liked human } \\
\text { sacrifices. Had had 'em } \\
\text { ages afore, but lost track o' } \\
\text { the upper world arter a } \\
\text { time. What they done to the } \\
\text { victims it ain't fer me to } \\
\text { say, an' I guess Obed } \\
\text { wa'n't none too sharp } \\
\text { abaout askin'. But it was } \\
\text { all right with the heathens, } \\
\text { because they'd ben havin' } \\
\text { a hard time an' was } \\
\text { desp'rate abaout } \\
\text { everything. They give a } \\
\text { sarten number o' young } \\
\text { folks to the sea-things twict } \\
\text { every year - May-Eve an' }\end{array}$ & $\begin{array}{l}\text { назывался остров - } \\
\text { приносили своих юношей } \\
\text { и девушек в жертву } \\
\text { неведомым богам, } \\
\text { живущим в морской } \\
\text { пучине, а те взамен } \\
\text { ниспосылали им свое } \\
\text { благоволение. Абед } \\
\text { решил, что изображения } \\
\text { страшных чудовищ на } \\
\text { вулканическом острове } \\
\text { как-то связаны с этими } \\
\text { богами. Те, возможно, } \\
\text { были амфибиями - отсюда } \\
\text { и все эти русалочьи } \\
\text { рассказы. Толковали, что } \\
\text { на дне моря у них целые } \\
\text { города. Маленький } \\
\text { вулканический остров, что } \\
\text { поднялся из глубины, как } \\
\text { раз оттуда. А в каменных } \\
\text { жилищах, от которых } \\
\text { остались одни развалины, } \\
\text { эти существа жили. Кто-то } \\
\text { из них жил на том месте, } \\
\text { которое островом } \\
\text { поднялось над водой. } \\
\text { Туземцы с Канаки увидели } \\
\text { их, объяснились знаками и } \\
\text { заключили сделку. } \\
\text { Этим лягушкам пришлись } \\
\text { по нраву человеческие } \\
\text { жертвоприношения. } \\
\text { За долгие годы под водой } \\
\text { они совсем утратили связь } \\
\text { с землей. Никто не видел, } \\
\text { что они делают с } \\
\text { жертвами, и я думаю, } \\
\text { капитан Абед был } \\
\text { достаточно умен, чтобы не } \\
\text { расспрашивать об этом. } \\
\text { Жертвы приносились } \\
\text { дважды в год - на первое } \\
\text { мая и на тридцать первое } \\
\text { октября, в канун Дня всех } \\
\text { святых. Кроме того, }\end{array}$ & 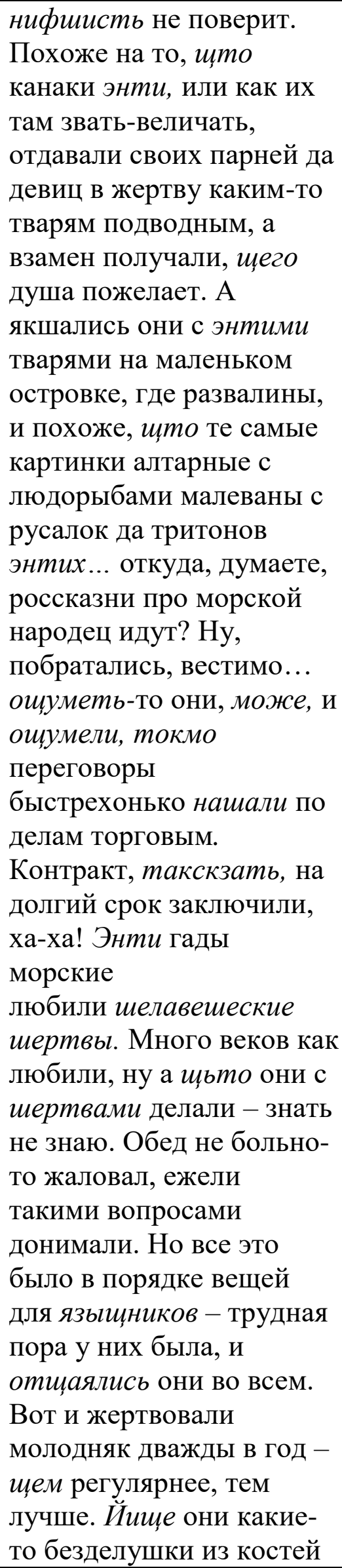 \\
\hline
\end{tabular}




\begin{tabular}{|c|c|c|}
\hline $\begin{array}{l}\text { Hallowe'en - reg'lar as cud } \\
\text { be. Also give some o' the } \\
\text { carved knick-knacks they } \\
\text { made. What the things } \\
\text { agreed to give in return was } \\
\text { plenty o' fish - they druv } \\
\text { 'em in from all over the sea } \\
\text { - an' a few gold-like things } \\
\text { naow an' then». }\end{array}$ & $\begin{array}{l}\text { существам } \\
\text { преподносились } \\
\text { полюбившиеся им резные } \\
\text { безделушки - изделия } \\
\text { местных умельцев. Они же } \\
\text { обязались подгонять к } \\
\text { острову рыбу и сдержали } \\
\text { слово - рыба со всего } \\
\text { моря круглый год кишела } \\
\text { у тамошних берегов. И } \\
\text { еще они время от времени } \\
\text { дарили туземцам разные } \\
\text { золотые вещи. }\end{array}$ & $\begin{array}{l}\text { вытачивали. В обмен те } \\
\text { твари им соглашались } \\
\text { достаточно рыбы давать } \\
\text { - им-то ее с моря согнать } \\
\text { была пара пустяков; ну и } \\
\text { златых щтущекк } \\
\text { подбрасывали - ныне и } \\
\text { присно. }\end{array}$ \\
\hline
\end{tabular}

Очевидно, что в оригинале английская речь одного из героев повести, полуграмотного старца-рыбака, изобилует лексическими ошибками, ошибками построения предложений и т. д. В переводе на русский Валерии Бернацкой все эти особенности речи персонажа не нашли никакого отражения. Совместный перевод Сергея Харитонова и Юрия Розвадовского выполнен с использованием небезынтересного приема - просторечия были выделены в тексте курсивом, что еще более подчеркивало их «неправильность», и, в целом, были достаточно удачно адаптированы при помощи фонетизированной записи некоторых слов и просторечных элементов.

Почти все европейские языки (не считая, к примеру, норвежского) к началу двадцатого столетия обрели официально зафиксированную письменнолитературную норму языка, обусловившую окончательное формирование типологизированных типов текста, основанных на означенной определенной норме (здесь, в первую очередь, подразумеваются научные и научнотехнические тексты) [5].

Образование приоритетной нормы послужило изменениям в понятии о переводе, которые не могут быть оценены как однозначно положительные. Рассмотренный выше отрывок из перевода повести Лавкрафта - достаточно наглядный пример подобного искусственного и необязательного «приведения к норме», ныне однозначно демонстрирующий невысокий уровень переводческого мастерства и небрежное отношение к букве оригинала. Языковое своеобразие первоисточника и индивидуальный авторский стиль при подобном «сглаженном» подходе не учитываются. 
Достаточно долгое время соблюдение литературной нормы языка даже в тех случаях, когда это не предусмотрено самим автором, считалось своего рода хорошим переводческим тоном, и только в последнее время подобный подход все чаще подвергается основательной критике при обсуждении наиболее состоятельных переводческих приемов и стратегий, а также наиболее действенной переводческой методологии.

\section{Список литературы}

1. Бреева, Л. В. Лексико-стилистические трансформации при переводе/ Л. В. Бреева, А. А. Бутенко. - Режим доступа: http://www.Belpaese 2000.narod.ru/Trad/trasform01.htm. - Загл. с экрана.

2. В творческой лаборатории Чехова / Акад. наук СССР, Ин-т мировой лит. им. А. М. Горького ; редкол: Л. Д. Опульская [и др.]. - М. : Наука, 1974. $367 \mathrm{c}$.

3. Кукла-чудовище : [сб.] / сост. О. Мумин, В. Фадеев ; пер. с англ. С. Харитонова, Ю. Розвадовского. - Ташкент : Фарангис, 1993. - 544, [4] с.

4. Лавкрафт, Г. Хребты безумия : [сб. : пер. с англ.] / Г. Лавкрафт. - М. : АСТ : ХРАНИТЕЛЬ, 2007. - 1164, [4] с.

5. Литературная энциклопедия. В 11 т. Т. 9 / гл. ред. А. В. Луначарский. - М. : Советская энциклопедия, 1935. - 832 с

6. Переводческие трансформации : портал переводчика. - Режим доступа: http://ranslations.web-3.ru/intro/equivalents/. - Данные соответствуют 2018 г.

7. Lovecraft, H. P. The Shadow Over Innsmouth (public domain) / H. P. Lovecraft. - Режим доступа: http://www.hplovecraft. com/writings/texts/ fiction/soi.aspx. - Загл. с экрана. 